\title{
Una aproximación al concepto de discurso del odio*
}

\section{An approach to the concept of hate speech}

SUMARIO

Introducción. I. El discurso del odio en el derecho internacional de los derechos humanos. II. El discurso del odio como atentado contra la dignidad humana y contra la diversidad como valor de las sociedades. III. El tratamiento del discurso del odio por la jurisprudencia de la Corte Suprema de Estados Unidos y del Tribunal Europeo de Derechos Humanos. Conclusión.

\section{RESUMEN}

En el presente trabajo se analizan los instrumentos internacionales más importantes que se ocupan de la definición y límites del discurso del odio, constatándose la falta de certeza y claridad frente a la aplicación, por parte de los tribunales, de prohibiciones a las diferentes manifestaciones que atentan contra un grupo minoritario, bien sea desde el punto de vista étnico, cultural, racial, religioso o cualquier otro, incluyendo la orientación sexual. Como ejemplo de lo anterior, se citan diferentes casos correspondientes a la Corte Suprema de Estados Unidos, la cual utiliza el criterio de la violencia inminente o estándar Brandenburg para valorar la ilicitud de un determinado comportamiento, frente a la jurisprudencia del Tribunal Europeo de Derechos Humanos que opta por un espectro más amplio al prohibir el discurso del odio. Ante ese panorama, en este artículo se acude a criterios doctrinales para resaltar la trascendencia de principios fundantes de la sociedad democrática como la justicia y la dignidad humana, con la finalidad de precisar el conte-

* $\quad$ Recibido el 10 de octubre de 2014, aprobado el 11 de febrero de 2015.

Para citar el artículo: J. M. Díaz Soto. Una aproximación al concepto de discurso del odio. Revista Derecho del Estado . $^{\circ}$ 34, Universidad Externado de Colombia, enero-junio de 2015 , pp. 77-101. DOI: 10.18601/01229893.n34.05

** Doctorando en Derecho de la Universidad Pompeu Fabra (Barcelona), docente e investigador adscrito al Departamento de Derecho Penal y Criminología de la Universidad Externado de Colombia. Contacto: diazsoto@hotmail.com 
nido del discurso del odio, de acuerdo a lo sostenido por JEREMY WALDRON, respecto de lo que debe entenderse como una "sociedad bien ordenada".

PALABRAS CLAVE

Discurso del odio, dignidad humana, justicia, criterio de la violencia inminente, libertad de expresión.

\section{ABSTRACT}

The actual work will consider the most important and relevant international instruments gathering the concept and limits of the hate speech, confirming the lack of sureness and perspicuity in the application, from the courts, of prohibitions towards the different discourses against minorities, either way from ethnical, cultural, racial religious or any other sight, including sexual orientation. As an example of this, there are different cases at the Supreme Court of the United States of America, that uses the criterion of inminent violence or Brandenburg standard to assess the wrongfulness of a particular demeanor, compared to the Jurisprudence of the European Court of Human Rights, which uses the wider parameter banning hate speech, even if it does not entail the incitement of imminent violence. From this perspective, this article calls for the doctrinal canons to highlight the importance of founding principles of a democratic society such as justice and human dignity, in order to specify the content of the hate speech.

\section{KEYWORDS}

Hate speech, human dignity, justice, inminent violence standard, freedom of speech.

\section{INTRODUCCIÓN}

La expresión discurso del odio o hate speech es empleada para designar acciones antijurídicas, o cuando menos inmorales, de la más diversa naturaleza. En efecto, bajo este concepto se ha identificado la quema de cruces en los barrios de personas de color ${ }^{1}$, la negación del Holocausto del pueblo judío

1 Actos intimidatorios realizados por miembros del Ku Klux Klan (КKK) en los barrios donde habitaban personas de raza negra. El Ku Klux Klan fue un grupo de extrema derecha creado en Estados Unidos hacia 1866 que profesaba ideas segregacionistas. Cfr. Klanwatch Proyect. Ku Klux Klan, A History of Racism and Violence, sixth edition, Montgomery, Alabama, Southern Poverty Law Center, 2011, p. 46. Puede consultarse en: http://www.splcenter.org/sites/default/ files/downloads/publication/Ku-Klux-Klan-A-History-of-Racism.pdf Recuperado el 7 de marzo de 2015 . 
durante la Segunda Guerra Mundial² y la promoción del exterminio del pueblo Tutsi que daría lugar al genocidio ocurrido en Ruanda en $1994^{[3]}$; hechos que si bien son todos censurables, guardan pocas características en común más allá de estar condicionados por motivos abyectos o, más exactamente, por el odio hacia una determinada colectividad.

Este escrito tiene como propósito profundizar en el estudio del concepto de discurso del odio, para lo cual se analizarán los principales instrumentos internacionales que, directa o indirectamente, se han ocupado de esta materia, tales como la Declaración Universal de los Derechos Humanos, la Convención para la Prevención y la Sanción del Delito de Genocidio; en América, el Pacto Internacional de Derechos Civiles y Políticos, y en Europa, el Convenio Europeo de Derechos Humanos y Recomendaciones Generales realizadas por la Comisión Europea contra el Racismo y la Intolerancia.

Así mismo, se abordará la obra de algunos doctrinantes que abogan por acotar el concepto de discurso del odio, con miras a su efectiva regulación sin sacrificar el ejercicio del derecho fundamental a la libertad de expresión. Dentro del estudio, también se tocará tangencialmente la dignidad humana y la diversidad como valores fundantes de las sociedades democráticas. El derecho a la libre expresión y el discurso del odio son los conceptos que se encuentran en pugna: ¿nos encontramos frente a un derecho absoluto? $¿ \mathrm{O}$ tal vez frente a una noción que limita un derecho de forma absoluta? Porque es evidente que el discurso del odio se erige como una forma de expresión de temas altamente sensibles, para la sociedad en general, expresado en racismo, xenofobia o discriminación: ¿hacen parte estas situaciones de lo que debe ser protegido dentro de la esfera de la libertad de expresión?

Por último se expondrá, sin pretensión de exhaustividad, el tratamiento dado a los fenómenos más comúnmente reconocidos como discurso del odio en el ámbito jurisprudencial, del Tribunal Europeo de Derechos Humanos y la Corte Suprema de Estados Unidos. Resultará provechoso para la aproximación al concepto de discurso del odio la posición diametralmente opuesta que profesan estos dos importantes tribunales de justicia.

2 El Holocausto del pueblo judío se dio a manos de Adolf Hitler y el movimiento nazi; la intención de aniquilar al pueblo judío se gestó no solo por parte de un líder sino también de amplios sectores de la sociedad alemana. Jorge Marco. "De genocidios, holocaustos, exterminios...", en Gutmaro Gómez Bravo (coord.), Hispania Nova. Revista de Historia Contemporánea n. ${ }^{\circ} 10,2012$, pp. $1-32$.

3 Genocidio ruandés a manos del poder oficial, milicias y campesinos hutus contra el pueblo tutsi. ERIC LaIR. "Reflexiones acerca del terror en los escenarios de guerra interna", Revista de Estudios Sociales n. ${ }^{\circ}$ 15, junio, 2003, pp. 88-108. 
I. EL DISCURSO DEL ODIO EN EL DERECHO INTERNACIONAL

DE LOS DERECHOS HUMANOS

El artículo 19 de la Declaración Universal de los Derechos Humanos, aprobada el 10 de diciembre de 1948, establece que toda persona tiene derecho a la libertad de expresión y opinión; derecho que comporta la garantía de no interferencia por parte del Estado y la libertad de recibir y transmitir información e ideas por cualquier medio. Sin duda se trata de un reconocimiento amplio del derecho a la libertad de expresión, hasta el punto que la Asamblea General no incluyó ninguna limitación expresa a su ejercicio. Esto, en opinión de Roger KISKA ${ }^{4}$, no constituye una inconsciente omisión de sus redactores, sino que refleja la derrota en el seno de la Asamblea de la posición sostenida por delegados de la Unión de Repúblicas Socialistas Soviéticas, que abogaban por la limitación del ejercicio de la libertad de expresión con base en consideraciones que se acercan a lo que actualmente se entiende por discurso del odio.

En otras palabras, la Declaración Universal de Derechos Humanos, según lo entiende KISKA, proscribe la limitación del ejercicio de la libertad de expresión, en menoscabo de la prohibición del discurso del odio, teniendo en cuenta que tal posibilidad fue debatida y rechazada durante el proceso de redacción de la Declaración. Como argumento a favor de esta interpretación se aduce la intervención del delegado soviético durante los trabajos preparatorios, AleXANDER Bomogolov, quien sostuvo que "no puede afirmarse que prohibir la incitación al odio por motivos de raza, nacionalidad o religión constituya una violación a la libertad de prensa o de expresión"s; pensamiento que sin duda se asemeja a las actuales consideraciones a favor de la prohibición del discurso del odio y cuya ausencia en el texto del artículo 19 puede dar lugar a una hermenéutica como la antes reseñada.

Otro sector de la doctrina, por el contrario, encuentra en el texto de la Declaración suficientes argumentos para sostener que este instrumento internacional proscribe el discurso del odio y que esta forma de expresión no está amparada por su artículo 19. Así, por ejemplo, PÉREZ-MADRID afirma que la prohibición del discurso del odio se funda en el reconocimiento de la dignidad humana -art. 1. ${ }^{\circ}$ DUDH-, en la garantía del goce igualitario de los derechos y libertades "sin distinción alguna de raza, color [o] sexo" -art. 2. ibíd.-, en la protección contra la discriminación y contra la incitación a la discriminación -art. 7. ${ }^{\circ}$ ibíd.- y, finalmente, en el artículo 29 que prevé la existencia de deberes consustanciales al ejercicio de los derechos y admite

4 Cfr. Roger Kiska. "Hate speech: A comparison between the European Court of Human Rights and the United States Supreme Court jurisprudence", Regent University Law Review, vol. 25:107, pp. 117 ss.

5 Traducción del autor. Citado en KISKa. Ob. cit., p. 118. 
la posibilidad de imponer limitaciones a tal ejercicio en procura del "reconocimiento y el respeto de los derechos y libertades de los demás"6.

Considero que si se valora la Declaración a la luz de los criterios para la interpretación de los tratados previstos en la Convención de Viena ${ }^{7}$, debe compartirse la hermenéutica sistemática propuesta por la autora antes citada, esto es, que la Declaración no reconoce la libertad de expresión como un derecho carente de limitaciones y que dentro de dichos límites podría ubicarse, precisamente, la prohibición del discurso del odio. Lo anterior, por lo demás, se compadece con la jurisprudencia norteamericana acerca del alcance de la libertad de expresión que imperaba para la época en que se adoptó la Declaración ${ }^{8}$.

Continuando con el análisis de los instrumentos internacionales relacionados con la materia objeto de análisis, cabe destacar la Convención para la Prevención y la Sanción del Delito de Genocidio, también adoptada en 1948, que en su artículo $3 .^{\circ}$ expresamente prevé que será punible la "instigación directa y pública a cometer genocidio"; crimen internacional que supone la intención de destruir, total o parcialmente, a un grupo nacional, étnico, racial o religioso. Lo anterior, sin duda constituye una limitación legítima al ejercicio de la libertad de expresión en atención a la salvaguarda de valores básicos de la comunidad internacional, y pone de presente que ciertas formas de discurso especialmente abyectas pueden y deben ser objeto de sanciones penales.

Con un mayor alcance, el artículo 20,2 del Pacto Internacional de Derechos Civiles y Políticos (PIDCP), aprobado el 19 de diciembre de 1966, preceptúa: "Toda apología del odio nacional, racial o religioso que constituya incitación a la discriminación, la hostilidad o la violencia estará prohibida por la ley". Nótese que no solo se prevé la posibilidad de limitar el ejercicio de la libertad de expresión, sino que se impone a los Estados Parte el deber de hacerlo en los eventos antes reseñados. Adicionalmente cabe destacar que tal limitación no opera únicamente frente a aquellos discursos llamados a generar reacciones violentas, sino también ante expresiones tendientes a la discriminación de un grupo o la creación de un ambiente hostil en su contra.

6 Cfr. Francisca PéRe-Madrid. "Incitación al odio religioso o 'hate speech' y libertad de expresión”, Revista General de Derecho Canónico y Derecho Eclesiástico del Estado, n. ${ }^{\circ} 19$, 2009 , p. 5.

7 Convención de Viena sobre el Derecho de los Tratados U.N. Doc A/CONF.39/27 (1969), 1155 U.N.T.S. 331.

8 En efecto, tanto en Chaplinsky v. New Hampshire (1942) como en Beauharnais v. People of the State of illinios (1952) la Corte Suprema de Estados Unidos adoptó un enfoque restrictivo frente al discurso del odio, similar al que impera hoy en el ámbito del Consejo de Europa. Para una detallada reseña de los fallos, ver Álvaro Paul Díaz. "La penalización de la incitación al odio a la luz de la jurisprudencia comparada", Revista Chilena de Derecho, vol. 38, n. ${ }^{\circ} 3,2011$, pp. 573-609. 
Como se observa, se trata de una restricción amplia al ejercicio de la libertad de expresión, aunque no por ello ilegítima, lo que ha llevado a algún autor a sostener que esta disposición es fruto de la influencia de Estados totalitarios y que socava los derechos reconocidos en la Declaración Universal de los Derechos Humanos ${ }^{9}$; sin embargo, esta parece ser una posición minoritaria en la doctrina.

En desarrollo de lo ya consagrado en el PIDCP, la "Convención Internacional sobre la eliminación de todas las formas de discriminación racial", adoptada el 21 de diciembre de 1965, prevé en su artículo 4, a) como acto punible conforme a la ley "toda difusión de ideas basadas en la superioridad o en el odio racial, toda incitación a la discriminación racial, así como todo acto de violencia o toda incitación a cometer tales actos contra cualquier raza o grupo de personas de otro color u origen étnico, y toda asistencia a las actividades racistas, incluida su financiación". Adviértase que conforme al texto transcrito, y a diferencia de lo consagrado en el PIDCP, la proscripción del discurso del odio o de la superioridad racial no está sujeta a la incitación a la discriminación. En otras palabras, se trata de una auténtica sanción por un mero acto de habla, con independencia de su trascendencia social en el caso en concreto, pues para su sanción no se exige, se reitera, que las expresiones de odio racial den lugar a actos de violencia o de discriminación ${ }^{10}$. Desde la perspectiva del derecho penal, podría decirse que la Convención bajo análisis pretende que sus Estados Parte adopten tipos penales de peligro con miras a la sanción de la difusión del discurso del odio racial, de modo que el injusto de este tipo de comportamientos se valore a partir de su potencial lesividad para los bienes jurídicos penalmente tutelables, sin que se exija el efectivo menoscabo de los mismos.

Un enfoque más restrictivo frente a la sanción del discurso del odio se advierte en la "Declaración sobre la eliminación de todas las formas de intolerancia y discriminación fundadas en la religión o en las convicciones", aprobada el 25 de noviembre de 1981, en la que respecto al tema que nos ocupa se señala en su artículo 2. :

1. Nadie será objeto de discriminación por motivo de religión o convicciones por parte de ningún Estado, institución, grupo de personas o particulares. 2. A los efectos de la presente Declaración, se entiende por "intolerancia y discriminación basadas en la religión o en las convicciones" toda distinción, exclusión, restricción o preferencia fundada en la religión o en las convicciones y cuyo fin o efecto sea la abolición o el menoscabo del reconocimiento, el goce o el ejercicio en pie de igualdad de los derechos humanos y las libertades fundamentales.

9 Cfr. KisKa. Ob. cit. p. 119 ss.

10 Esta misma interpretación de la Declaración puede encontrarse en PéREZ-MADRID. Ob. cit., p. 8 . 
De la lectura de los apartes transcritos se desprende que lo que es objeto de prohibición conforme a esta Declaración es el trato discriminatorio fundado en la identidad religiosa, y no la mera difusión de ideas contrarias a una creencia religiosa en particular.

Del análisis comparado de los dos instrumentos internacionales antes reseñados es posible advertir un mayor margen para la discusión de los asuntos religiosos que de cuestiones de carácter racial o étnico, pues, como se acaba de señalar, la "Convención Internacional sobre la eliminación de todas las formas de discriminación racial" proscribe la mera difusión de ideas racistas, en tanto que las manifestaciones en contra de una creencia religiosa solo son censurables de acuerdo con la Declaración cuando estén encaminadas a la exclusión social de un determinado grupo religioso.

Lo anterior obedece, en mi concepto, a que los asuntos religiosos son por esencia objeto de discusión, es más, la libertad de culto pasa por la posibilidad de cuestionar la validez de los dogmas espirituales ajenos e intentar convencer a los demás del acierto de los nuestros; precisamente así lo consideró el Tribunal Europeo de Derechos Humanos al afirmar que la posibilidad de intentar acercar a los demás a nuestra fe constituye una libertad sin la cual el artículo 9. ${ }^{\circ}$ del Convenio Europeo de Derechos Humanos "no sería más que letra muerta" 11 .

En igual sentido se ha pronunciado la Asamblea Parlamentaria del Consejo de Europa, que en su Resolución 1510 del 28 de junio de 2006, sobre la libertad de expresión y el respeto a la creencias religiosas, declaró, en palabras de MarTín SÁnCHEZ, "que la libertad de expresión, tal y como está regulada en el artículo 10. del Convenio Europeo de Derechos Humanos, no debe ser restringida para proteger la creciente sensibilidad de algunos grupos religiosos"12.

Por el contrario, todo discurso que tenga por objeto fomentar el odio o la discriminación hacia una determinada raza o grupo étnico es censurable. En otras palabras, nuestra sociedad no admite ningún margen de discusión acerca de la superioridad racial o la existencia de ciertos atributos negativos en los miembros de una colectividad por el simple hecho de pertenecer a ella, pues tales afirmaciones, como se expondrá más adelante, nada aportan al debate de los asuntos públicos y, por el contrario, menoscaban el principio de dignidad humana.

Esta perspectiva puede advertirse en las declaraciones de distintos organismos europeos de defensa de derechos humanos. Así, por ejemplo, la Comisión Europea contra el Racismo y la Intolerancia, creada por el Consejo

11 Cfr. Sentencia sobre el caso Kokkinakis c. Grecia de 25 de mayo de 1993, n. 17. Reseñada por KISKA. Ob. cit., p. 133.

12 Isidoro Martín SÁnchez. "El discurso del odio en el ámbito del Consejo de Europa", Revista General de Derecho Canónico y Derecho Eclesiástico del Estado n. ${ }^{\circ} 28,2012$, p. 6. 
de Europa, sostuvo en su Recomendación General n..$^{\circ}$, del 13 de diciembre de 2002, que los Estados miembros deberían adoptar sanciones penales para combatir la difusión de expresiones racistas, aun cuando las mismas no tuvieran como propósito específico la incitación a la violencia contra una minoría. En palabras de MARín SÁNCHEZ, "esta Recomendación General manifestó que la expresión pública con una finalidad racista, de una ideología racista o la negación pública con la misma finalidad de crímenes de genocidio, o contra la humanidad, o de guerra, también debería ser sancionada penalmente" ${ }^{13}$.

En todo caso, debe aclararse que la tolerancia al debate sobre los asuntos religiosos encuentra límite en la seguridad y dignidad de los creyentes, de modo que nada obsta para que las manifestaciones tendientes a estigmatizar con atributos antisociales a los miembros de una determinada religión se consideren una modalidad de discurso del odio y, por tanto, se prohíba su difusión. Así lo ha señalado, por ejemplo, la Comisión Europea para la Democracia mediante la Ley, órgano consultivo del Consejo de Europa que concluyó, tras su septuagésima sexta sesión plenaria ${ }^{14}$, que "la incitación al odio -incluido al odio religioso- debería ser objeto de sanciones penales, como sucede en casi todos los Estados europeos" 15 .

Ahora bien, en el ámbito regional cabría destacar la Convención Americana de Derechos Humanos, del 22 de noviembre de 1969, que en su artículo 13,5 preceptúa:

Estará prohibida por la ley toda propaganda a favor de la guerra y toda apología del odio nacional, racial o religioso que constituyan incitaciones a la violencia o cualquier otra acción ilegal similar contra cualquier persona o grupo de personas, por ningún motivo, inclusive los de raza, color, religión, idioma y origen nacional.

La norma transcrita permite advertir un tratamiento más restrictivo a la prohibición del discurso del odio que el consagrado en el PIDCP, pues solo establece para los Estados Parte la obligación de prohibir el discurso discriminatorio cuando constituya una incitación a la violencia o a una acción ilícita similar; lo que puede interpretarse como la permisión del discurso que aboga por la exclusión social de ciertos grupos por medios no violentos.

En el escenario europeo, el Convenio Europeo de Derechos Humanos, aprobado el 4 de noviembre 1950 , reconoce en su artículo $10 .^{\circ}$ el derecho a la libertad de expresión, el cual comporta la libertad de opinión, así como la de recibir y comunicar información e ideas. El inciso $2{ }^{\circ}$ del mentado artículo contiene un listado taxativo, aunque más o menos extenso, de motivos por los que la ley de los Estados Parte podría limitar el ejercicio de este dere-

13 Ibíd.,p. 5.

14 Que tuvo lugar los días 17 y 18 de octubre de 2008.

15 Citado por Martín SÁnchez. Ob. cit., p. 7. 
cho; finalidades entre las que no se encuentra expresamente la proscripción del discurso discriminatorio o racista. No obstante, bien podría encuadrarse esta finalidad en otras expresamente reconocidas en el Convenio, como "la protección de la reputación o los derechos ajenos" o "la defensa del orden y la prevención del delito". Como se expondrá más adelante, el Tribunal Europeo de Derechos Humanos ha considerado que el discurso del odio no encuentra protección en el artículo 10. ${ }^{\circ}$ del Convenio, es más, para el Tribunal expresiones de este tipo constituyen un auténtico caso de abuso del derecho proscrito en el artículo 17 ibíd.

También en el escenario del Consejo de Europa cabe destacar la Recomendación n. 97 (20) adoptada por el Comité de Ministros el 30 de octubre de 1997, en la que se definió el discurso del odio en los siguientes términos:

... cualquier forma de expresión que propague, incite, promueva o justifique el odio racial, la xenofobia, el antisemitismo y otras formas de odio basadas en la intolerancia, incluyendo la intolerancia manifestada mediante un nacionalismo y etnocentrismo agresivos, la discriminación y hostilidad contra las minorías, los inmigrantes y las personas de origen inmigrante.

Si se analiza con detenimiento la definición transcrita, se advierte que el objeto de censura radica en el discurso llamado a promover la intolerancia hacia grupos minoritarios, más que a proteger la sensibilidad de sus miembros a causa de, por ejemplo, epítetos racistas o insultos que tengan como base la identidad étnica, cultural o religiosa de la víctima. Así se advierte de las formas de intolerancia señaladas a modo enunciativo como modalidades de discurso del odio, esto es, el nacionalismo extremo y la discriminación u hostilidad contra minorías.

Esta interpretación, por lo demás, se compadece con el principio n. ${ }^{\circ} 3$ enunciado en la Recomendación, conforme al cual los Gobiernos de los Estados miembros deben asegurarse de que las injerencias en el derecho a la libertad de expresión que se consagren con miras a la prohibición del discurso del odio, se hallarán circunscritas estrictamente a esta materia y se aplicarán con sujeción al debido proceso y con base en criterios objetivos y no arbitrarios (“... interferences with freedom of expression are narrowly circumscribed and applied in a lawful and non-arbitrary manner on the basis of objective criteria").

De este breve resumen resulta válido concluir que el ejercicio de la libertad de expresión está sujeto a ciertos límites reconocidos desde el propio derecho internacional de los derechos humanos; en particular, se advierte que la incitación a la violencia por motivos discriminatorios se encuentra absolutamente proscrita, en especial si tal ejercicio de violencia se encamina a la comisión de un genocidio u otra modalidad de crímenes contra la humanidad. 
De igual modo, es posible advertir una marcada tendencia a la prohibición de la difusión de ideas racistas y, en general, de aquellas que pretenden la exclusión social de un grupo minoritario imputando a sus miembros atributos negativos; sin que sea necesario que tal discurso tenga como propósito la incitación a la violencia propiamente dicha.

Sin embargo, debe también concluirse que la comunidad internacional no ha acordado una definición de lo que debe entenderse por discurso del odio que cumpla con los atributos de claridad y certeza necesarios para invocarse como límite válido al ejercicio de la libertad de expresión; lo que resulta imperioso si se considera, como lo ha declarado el propio Tribunal Europeo de Derechos Humanos, que este derecho "es uno de los fundamentos esenciales de una sociedad democrática, además de una de las condiciones básicas para el progreso de la sociedad y el desarrollo de la persona"16.

En vista de lo anterior, considero que es necesario remitirse a la doctrina en búsqueda de luces acerca de la esencia del discurso del odio y los efectos que este genera en la sociedad y en los individuos hacia los cuales se dirige; a partir de lo cual podrá enunciarse una definición más precisa de este fenómeno con miras a su prohibición sin poner en riesgo el núcleo esencial de la libertad de expresión.

\section{EL DISCURSO DEL ODIO COMO ATENTADO CONTRA LA DIGNIDAD HUMANA Y CONTRA LA DIVERSIDAD COMO VALOR DE LAS SOCIEDADES}

En este acápite me detendré en el análisis de la obra del profesor JEREMY WALDRON The harm in hate speech ${ }^{17}$, quien considero brinda criterios bastante precisos acerca de lo que debe entenderse por discurso del odio en el escenario de las sociedades democráticas y explica de forma convincente por qué razón, en contravía del pensamiento mayoritario imperante en Estados Unidos, este tipo de manifestaciones deben ser prohibidas por la ley.

Para empezar, WALDRON reconoce que el concepto de discurso del odio es demasiado impreciso, en particular, que la referencia al término "odio" daría lugar a pensar que lo que es objeto de reproche es el sentimiento de animadversión o incomodidad que se puede experimentar hacia los miembros de un grupo minoritario. Si así fuera, la legislación en contra del discurso del odio abogaría por el "perfeccionamiento" del ser humano, de modo que bien podría ser tildada de antiliberal. Sin embargo, WALDRON aclara que los que, como él, abogan por la adopción de medidas legislativas en contra del discurso del odio no fundamentan su postura en consideraciones morales, sino en los efectos perversos que tal forma de discurso tiene en la configuración

16 Sentencia del caso Handyside c. el Reino Unido, n. 49. Especialmente crítico sobre la vaguedad de las definiciones propuestas se muestra KISKA. Ob. cit.

17 JeREMy WaLdROn. The harm in hate speech, London, Harvard University Press, 2012. 
de una sociedad democrática y en la dignidad de los individuos que integran las colectividades contra las que se dirige ${ }^{18}$.

Precisamente el rasgo definidor del discurso del odio, según WALDRON, es su capacidad para atentar contra la dignidad humana, entendida no en términos kantianos o absolutos sino como un particular estatus social que debe ser reafirmado por la ley para predicar su existencia. En relación con este concepto de dignidad, afirma WALDRON:

La dignidad de una persona no es solo un tipo de aura kantiana que lo cubre. Es su posición social, el fundamento de una reputación básica que le permite ser tratado como un igual en el curso ordinario de la sociedad. Su dignidad es algo en lo que puede confiar -en el mejor de los casos de forma implícita y sin necesidad de reclamarlo- mientras vive su vida, se ocupa de sus asuntos y cría a su familia ${ }^{19}$.

Así entendida, la dignidad se traduce en el reconocimiento que toda persona puede exigir a sus conciudadanos de su condición de individuo apto para la vida en sociedad; derecho que se ve menoscabado cuando las características raciales, religiosas o culturales del individuo son asociadas de forma indiscriminada con comportamientos antisociales. En palabras de W ALDRON:

... las leyes contra la difamación de un grupo o colectividad protegen el núcleo esencial de la reputación de cada persona contra intentos, por ejemplo, de asociar a todos los miembros de un grupo racial o religioso vulnerable con la comisión de graves actos criminales; imputación que de ser sostenida ampliamente privará a los miembros del grupo en cuestión del estatus de ciudadanos ${ }^{20}$.

\section{$[\ldots]$}

Debe presumirse que las personas son básicamente honestas y respetuosas de la ley, así como que sus atributos básicos - por ejemplo, ser hombre o mujer, blanco o negro, judío o cristiano- no las predisponen a incurrir en actos criminales o les atribuye un carácter antisocial ${ }^{21}$.

18 Cfr. ibíd., p. 37. Al respecto señala el autor en comento: "Quienes abogan por una legislación contra el discurso del odio no infieren la ilicitud de incitar el odio contra un grupo vulnerable de la inmoralidad del odio en sí [...]. Lo que les preocupa es la situación de las personas vulnerables que son sujetos del odio dirigido contra su raza, identidad étnica o religiosa; aparte de esa problemática, los partidarios de la legislación contra el discurso del odio no deben tener interés en el tema de la moralidad del odio en sî" (trad. del autor).

19 Ibíd., p. 5 (trad. del autor).

20 Ibíd., p. 47 (trad. del autor).

21 Ibíd., p. 53 (trad. del autor). 
WALDRON identifica cuatro formas que puede adoptar el discurso difamatorio contra una colectividad que, a su vez, lesiona la dignidad de sus miembros $\mathrm{y}$, por tanto, debería estar proscrito por la ley; a saber:

- La imputación de forma generalizada a los miembros de un grupo de la comisión de hechos ilícitos; como cuando se indica que todas las personas de color incurren en hurtos o violaciones.

- Mediante caracterizaciones que denigran de los miembros de la comunidad; como señalar que los judíos son avaros o maliciosos.

- A través de referencias a animales o cosas, de modo que se prive a los miembros de la colectividad atacada de su condición de seres humanos.

- Mediante prohibiciones en atención a los rasgos definidores del grupo, como prohibir la entrada a sitios públicos de personas de color ${ }^{22}$.

De forma singular o concurrente, estas modalidades de difamación contra un grupo atentan contra el estatuto social de sus miembros, quienes ya no podrán confiar en que la mayoría de la sociedad en que viven los acepte como seres humanos con capacidad para la vida en comunidad; como lo explica WALDRON:

Es una cuestión de estatus - del estatus propio como miembro de una colectividad en buena situación- que da lugar a demandar reconocimiento y un tratamiento acorde con ese estatus. Filosóficamente puede sostenerse que la dignidad es inherente al ser humano, y lo es, pero como estatus legal y social debe ser establecida, afirmada, mantenida y revindicada por la sociedad y la ley, y esto es algo en lo que todos estamos obligados a tomar parte. Cuando menos, estamos en la obligación de abstenernos en nuestro trato público con otros de actuar con miras a minar la dignidad de otras personas. Esta es la obligación a la que se le da carácter vinculante cuando se promulgan leyes contra la difamación de una colectividad.

En todo caso resulta necesario aclarar, como lo hace el propio WALDRON en el capítulo $5 .^{\circ}$ de su obra ${ }^{23}$, que lo que debe ser objeto de protección por las leyes que prohíben el discurso del odio es la dignidad de los miembros de las colectividades difamadas y no su sensibilidad. Los insultos y epítetos racistas, bajo ese entendido, no encuentran adecuación en el concepto de discurso del odio. En efecto, lo que se censura del discurso del odio es que agravia el estatus social de los miembros de las colectividades difamadas, de modo que solo aquellas publicaciones, manifestaciones y discursos públicos con aptitud para causar este efecto pueden catalogarse como ilícitas. En palabras de WALDRON: "Proteger a las personas de ser ofendidas equivale a protegerlas

22 Ibíd., p. 56 ss.

23 Titulado "protecting dignity or protection from offense?". Ibíd., p. 105-146. 
de ciertas clase de efectos en sus sentimientos. Y esto es distinto a proteger su dignidad y asegurar su trato decente en la sociedad"24.

Ahora bien, en lo que respecta a los efectos que WALDRON atribuye al discurso del odio en la configuración de nuestras sociedades, el autor adopta como baremo de valoración el concepto formulado por RAWLS de "sociedad bien ordenada" (well ordered society), esto es, aquella en que todos sus miembros aceptan y pueden confiar en que sus conciudadanos también aceptan los mismos principios de justicia ${ }^{25}$; se trata de un ideal al que debe propender toda sociedad auténticamente democrática.

Planteada así la noción de sociedad bien ordenada, WALDRON se pregunta si una sociedad en la que se admite sin mayores limitaciones el discurso del odio responde o no a este concepto. En su criterio, una sociedad bien ordenada debe adoptar un compromiso general con los principios de justicia y dignidad de que son titulares todos sus miembros; compromiso que en primer lugar se manifiesta en la forma en que se encuentra configurada dicha sociedad y se presenta a los ojos de sus ciudadanos ${ }^{26}$.

En consecuencia, todo lo que afecte la forma en que la sociedad se presenta ante sus ciudadanos y ponga en entredicho el compromiso de la sociedad con la dignidad de estos debe ser censurado. Al respecto, W ALDRON anota que el discurso del odio no es solamente un conjunto de ideas que confluye al debate público, sino que constituye una actividad definidora del entorno social haciendo para las minorías más difícil integrarse y, en general, desenvolverse en la sociedad ${ }^{27}$.

En otras palabras, la forma en que una sociedad se presenta públicamente constituye el principal modo de transmitir seguridad a sus miembros acerca de la vigencia del acuerdo esencial de abogar por la consolidación de una sociedad bien ordenada (compromiso de todos los ciudadanos con los mismos principios de justicia y dignidad). El discurso del odio atenta de forma grave contra esa confianza, en particular, lesiona el fundamento mismo de la idea de justicia en una sociedad, esto es, que todos somos igualmente humanos, gozamos de una dignidad inherente a nuestra condición humana y, por tanto, merecemos protección ante las formas más insidiosas de violencia, exclusión, indignidad y subordinación ${ }^{28}$. En palabras del WALDRON:

24 Ibíd.,p. 107.

25 Ibíd.,p. 69.

26 Ibíd.,p. 70.

27 Ibíd., p. 74. Sobre el particular afirma WALDRON: "la difamación racial o religiosa no es solo una idea que contribuye al debate público. Bajo la forma de publicaciones o exhibiciones públicas, el discurso del odio constituye una actividad definidora del entorno social mismo, y quienes lo promulgan lo saben bien, es parte de su intención que el mundo que crean sea mucho más difícil para las minorías que deben vivir en él" (trad. del autor).

28 Cfr. ibíd., p. 82. 
El punto de la auto representación visible de una sociedad bien ordenada no es meramente estético, se trata de una transmisión de confianza a todos los ciudadanos de que serán tratados justamente. Sin embargo, cuando una sociedad se ve desfigurada por signos antisemitas, cruces ardientes y panfletos difamatorios contra una raza, esta clase de seguridad se evapora. Las fuerzas de seguridad y la administración de justicia pueden aún proteger a la gente de ser atacada o excluida, pero ya no tendrán el beneficio de una seguridad general y difusa para este efecto, provista y disfrutada como un bien público, suministrada por todos para cada $u^{29}{ }^{29}$.

El aparte transcrito pone en evidencia que para WALDRON la posibilidad de confiar en la vigencia de los principios de justicia y dignidad propios de una sociedad bien ordenada es un auténtico bien público, cuyo aseguramiento no solo compete al Estado sino, en general, a todos los miembros de la sociedad. Por lo anterior, el Estado se encuentra legitimado para exigir a sus ciudadanos un mínimo de respeto hacia los miembros de grupos minoritarios, esto es, el llamado "respeto de reconocimiento" que se desprende de su condición de seres humanos y que resulta indispensable para la afirmación de la dignidad humana. Al respecto, afirma el autor:

El hecho de que podamos tener diferentes estimaciones de distintas personas como forma de respeto relacional no implica que no nos hallemos obligados a mantener el acuerdo social de predicar el respeto de reconocimiento por cada uno de los miembros de la sociedad ${ }^{30}$.

De este modo, WALDRON brinda una respuesta convincente a la pregunta de por qué ha de prohibirse el discurso del odio aun cuando no comporte la incitación al uso de la violencia. Ello es así porque, se reitera, el discurso del odio lesiona la dignidad de los individuos de las colectividades difamadas y, al hacerlo, desfigura la apariencia de la sociedad como colectividad comprometida con los más básicos principios de justicia; lo que la aleja de su ideal de sociedad bien ordenada.

En este mismo sentido de limitar la libertad de expresión se ha pronunciado Owen Fiss argumentando que las manifestaciones racistas o discriminatorias merman la libertad de expresión de las minorías; en ese entendido, la limitación de la libre expresión se daría en el marco de otorgar a todos el respeto de sus derechos; "a veces debemos aminorar las voces de algunos para poder oír las voces de los demás"31. Autores como RafAel AlCÁcER DE GUIRAO

29 Ibíd.,p. 84 (trad. del autor).

30 Ibíd.,p. 87.

31 Owen FIss. The Irony of Free Speech, Cambrigde, MA, Harvard University Press, 1996, p. 30 . 
sostienen que planteamientos como los de Fiss no son razón suficiente para restringir la libertad de expresión por medio de la sanción penal, a menos que el contexto por el que atraviese la sociedad represente una desigualdad flagrante entre los colectivos sociales que impida un "discurso de defensa" contra el "discurso de odio" 32 .

\section{EL TRATAMIENTO DEL DISCURSO DEL ODIO POR LA JURISPRUDENCIA DE LA CORTE SUPREMA DE ESTADOS UNIDOS Y DEL TRIBUNAL EUROPEO DE DERECHOS HUMANOS}

Son varios los autores que identifican en la jurisprudencia de la Corte Suprema de Estados Unidos la fuente de inspiración del Tribunal Europeo de Derechos Humanos (TEDH) en lo que hace a la libertad de expresión. En particular, la idea de que la libertad de expresión es uno de los fundamentos esenciales de las sociedades democráticas y que no solo ampara las manifestaciones favorables o inocuas, sino también aquellas capaces de "ofender, sacudir o molestar" 33 , puede evidenciarse en la jurisprudencia del Tribunal Supremo norteamericano desde inicios de los años sesenta ${ }^{34}$, esto es, más de una década antes de las decisiones que se consideran como los cimientos de la jurisprudencia del TEDH $^{35}$ en esta materia.

\section{Al respecto, ha señalado Revenga SÁnchez:}

... las dos decisiones "fundacionales" de la doctrina del TEDH en la materia beben en idéntica fuente y comparten un mismo presupuesto, en diálogo con el cual parece desarrollarse la jurisprudencia posterior. La fuente es, claro está, el Tribunal Supremo norteamericano; el presupuesto, la idea de que la libertad de expresión ocupa en las sociedades democráticas una posición privilegiada que, en principio, basta para socavar la legitimidad de lo que vaya contra ella ${ }^{36}$.

32 Rafael Alcácer Guirao. "Discurso del odio y discurso político: En defensa de la libertad de los intolerantes", Revisa Electrónica de Ciencia Penal y Criminología, n. ${ }^{\text {14-02, }}$ 2012, p. 02:30. Disponible en: http://criminet.ugr.es/recpc/14/recpc14-02.pdf. Recuperado el 7 de marzo de 2015.

33 Tribunal Europeo de Derechos Humanos, decisión del caso Handyside c. El Reino Unido [1979] n. 49.

34 Sin duda la decisión hito en la materia la constituye New York Times v. Sullivan (1964), en la que la Corte Suprema consideró: "la discusión sobre los asuntos públicos ha de ser desinhibida, consciente y amplia, de manera que la misma bien puede conllevar críticas vehementes o casuísticas, así como ataques incisivos que resulten poco gratos para el Gobierno y para quienes desempeñan cargos públicos": New York Times v. Sullivan, 376 US (1964), 254, 270.

35 Cfr. Miguel Revenga Sánchez. "Algunos apuntes sobre la doctrina del Tribunal Europeo de Derechos Humanos en materia de libertad de expresión”, en AA.VV., Miguel ReVEnga SÁnCHEZ y Andrée Viana Garcés (eds.), Tendencias jurisprudenciales de la Corte Interamericana y el Tribunal Europeo de Derechos Humanos, Valencia, Tirant lo Blanch, 2008.

36 Ibíd., p. 208. 
No obstante, en lo que respecta al discurso del odio el diálogo entre el máximo tribunal norteamericano y el TEDH se rompe por completo. En efecto, la Corte Suprema de Estados Unidos ha adoptado frente al discurso del odio, cuando menos desde finales de los años sesenta, lo que algún sector de la doctrina denomina "enfoque liberal" ${ }^{37}$, conforme al cual el valor otorgado a la libertad de expresión como pilar de toda sociedad democrática debe conducir a una mayor tolerancia de las autoridades gubernamentales frente a este tipo de manifestaciones.

La sentencia hito en la materia es Brandenburg vs. Ohio (1969), en la que la Corte Suprema modificó su jurisprudencia frente al discurso del odio y adoptó el que continúa siendo el criterio vigente para valorar su licitud, esto es, el llamado criterio de la violencia inminente, o estándar Brandenburg. El caso se refería a un dirigente del Ku Klux Klan que en una reunión de dicha organización, filmada y retransmitida por un medio de comunicación, difundió ideas racistas que en el contexto en que tuvo lugar el discurso podían interpretarse como una incitación a la violencia contra grupos minoritarios, en particular, contra las personas de color y contra los judíos. Esta persona fue condenada a pena de prisión y multa conforme a una ley del Estado de Ohio que prohibía incitar al uso de la violencia como medio para lograr reformas laborales o políticas. Al llegar el caso a la Corte Suprema, la misma estimó que la ley estatal resultaba contraria a la primera enmienda, en especial, que expresiones como las analizadas solo podían ser reprimidas por la ley si estaban "dirigidas a incitar o producir inminentes acciones desenfrenadas (lawlees), y es probable que las incite y produzca" 38 .

Lo considerado por la Corte Suprema en la decisión reseñada ha sido reiterado a lo largo de las últimas cuatro décadas. Así, por ejemplo, en Collin vs. Smith (1978) la Corte de Apelaciones del 7. . Circuito consideró, entre otros argumentos, que el uso de la esvástica y otros símbolos nazis en una manifestación pública estaba amparado por la primera enmienda, pues tales expresiones no podían considerarse como una incitación inminente al uso de la violencia ni caían en el concepto de palabras pendencieras (fighting words), esto es, "las que por el solo hecho de ser proferidas, infligen daño o tienden a incitar un inmediato quiebre de la paz" ${ }^{39}$. Atendiendo a estos argumentos, la Corte de Apelaciones declaró que los reglamentos adoptados por las autoridades del poblado de Skokie, Illinois, que prohibían manifestaciones públicas en las que se empleara simbología de esta naturaleza, resultaban contrarios a la Constitución, y en consecuencia autorizó la manifestación del así denominado "Partido Nacional Socialista de América" en la mencionada

37 Cfr. Álvaro Paúl Díaz. "The criminalization of hate speech in chile in light of comparative case law", Revista Chilena De Derecho, vol. 38, n. . 2, 2011, p. 576.

38 Brandenburg v. Ohio (1969), citada por Paúl Díaz. Ob. cit., p. 578.

39 Ibíd., p. 574. 
población, y ello a pesar de que la mayor parte de sus habitantes profesaban la fe judía y algunos inclusos habían sobrevivido al Holocausto. Estas consideraciones fueron tácitamente respaldadas por la Corte Suprema que se abstuvo de conocer el caso en sede de certiorari; decisión que contó con los votos disidentes de los magistrados BLACKMUN y White ${ }^{40}$.

Más recientemente, en el caso Snyder vs. Phelps et al. (2011), la Corte Suprema reiteró el enfoque liberal frente al hate speech al considerar que los miembros de un grupo religioso no comprometieron su responsabilidad civil extracontractual al protagonizar una manifestación durante el funeral de un marine que profesaba la fe católica y a su vez era homosexual; manifestación en la que lanzaron arengas contra la tolerancia de la homosexualidad en las Fuerzas Armadas, los homosexuales y la fe católica. En particular, la Corte confirmó la sentencia que en segunda instancia había revocado la indemnización otorgada a los familiares del fallecido por daños morales y punitivos, pues, en criterio de la Corte, la manifestación tenía por objeto temas de interés público; razón por la cual se encontraba respaldada por la primera enmienda. La sentencia solo contó con el voto disidente del magistrado Alito, quien consideró que si bien la primera enmienda autoriza la difusión de ideas como las expresadas por los demandados, no faculta para infligir intencionalmente daños morales a personas que se encuentren pasando por un momento difícil mediante crueles ataques verbales que en nada contribuyen al debate público ${ }^{41}$.

Por el contrario, el Tribunal Europeo de Derechos Humanos parte de una premisa absolutamente opuesta, según la cual el discurso del odio no encuentra fundamento en el derecho a la libertad de expresión conforme a su consagración en el Convenio Europeo de Derechos Humanos (en adelante, "el Convenio"). Es más, para el Tribunal tales manifestaciones constituyen un auténtico caso de abuso del derecho, es decir, de ejercicio de las libertades reconocidas en el Convenio para atentar contra los valores esenciales en que se funda; opción abiertamente proscrita por el artículo 17. Al respecto explica Revenga SÁnchez:

Mediante el recurso al artículo 17 del Convenio, en el que se establece la prohibición de aquellas actividades dirigidas a la destrucción del sistema de los derechos recogidos en el mismo (prohibición al abuso del derecho), el Tribunal Europeo de Derechos Humanos parece cada vez más decidido a definir aquello que el Convenio no ampara en ningún caso. O dicho de otro modo, el Tribunal parece estar interesado en delinear un ámbito de intransigencia establecido a priori, y capaz de reforzar el sistema de restricciones establecidas al ejercicio de

40 El voto disidente de los magistrados puede consultarse en: http://caselaw.lp.findlaw. $\mathrm{com} / \mathrm{scripts} /$ getcase.pl?court=us\&vol=439\&invol=916 Recuperado el 16 de septiembre de 2013.

41 El voto disidente del magistrado Alito puede consultarse en: http://www.law.cornell. edu/supct/html/09-751.ZD.html Recuperado el 16 de septiembre de 2013. 
determinados derechos, hasta el punto de justificar un discurso argumentativo que pueda soslayar una consideración detenida de tal sistema. Así viene sucediendo en los casos de discursos susceptibles de alentar sentimientos de carácter racista (y especialmente antisemita, al hilo de versiones sesgadas de nuestro inmediato pasado), así como, en general, y de manera creciente, con respecto a actitudes de complicidad o complacencia con la violencia terrorista ${ }^{42}$ (resaltado fuera de texto).

La identificación del discurso del odio como una modalidad de abuso del derecho tiene trascendentales consecuencias en la praxis jurisprudencial, pues su prohibición por los Estados Parte no se valorará conforme a los criterios previstos para establecer la convencionalidad de las restricciones al ejercicio del derecho a la libertad de expresión, sino que se dará por sentado que se trata de una forma de discurso que escapa al ámbito de protección del Convenio y, en consecuencia, su proscripción resulta legítima.

En efecto, los casos conocidos por el TEDH que realmente se adecuan a la noción aquí esbozada de discurso del odio, se resuelven atendiendo a la institución del abuso del derecho y, por lo general, terminan con decisión de inadmisibilidad de la demanda ${ }^{43}$, por el contrario, la prohibición y sanción por los Estados miembros de otro tipo de manifestaciones, como la incitación o la justificación del uso de la violencia contra el Gobierno, conlleva un análisis más estricto por parte del TEDH en el que se valorará la necesidad de la injerencia a la luz de los criterios establecidos en el parágrafo $2 .^{\circ}$ del artículo $10 .^{\circ}$, así como la proporcionalidad de tal restricción.

Así, por ejemplo, la mayor parte de los casos promovidos contra Turquía en razón de la imposición de sanciones penales por la difusión de ideas consideradas subversivas, han sido valorados por el TEDH a la luz de la segunda de las metodologías expuestas, esto es, analizando la necesidad y proporcionalidad de la medida y sin acudir a la institución del abuso del derecho. Es más, en estos casos el verdadero criterio de valoración de la convencionalidad de la injerencia es la aptitud del discurso para promover la violencia, más que la incitación al odio o su contenido discriminatorio. Así, por ejemplo, en Karatas c. Turquía (1999) el TEDH consideró que la condena contra el autor de un libro de poemas sobre la situación del Kurdistán resultaba contraria al Convenio, pues se trataba de un asunto de interés público, y aunque algunos pasajes del libro tenían un tono agresivo y llamaban al uso de la violencia, el carácter artístico de la obra le restaba aptitud para convocar a la insurrección.

42 Revenga SÁnchez. Ob. cit., p. 214. Esta interpretación de la jurisprudencia del TEDH puede también advertirse en Martín Sánchez. Ob. cit., p. 9, y en PéreZ-Madrid. Ob. cit., p. 17.

43 Así lo advierte del análisis de la jurisprudencia del Tribunal Europeo de Derechos Humanos. MarTín SÁnchez. Ob. cit., p. 9. 
Nótese que en el caso reseñado, y en otros similares conocidos por el $\mathrm{TEDH}^{44}$, no nos hallamos ante un auténtico supuesto de discurso del odio, a pesar de que las expresiones censuradas pueden tener como propósito incentivar el odio contra un grupo. Como lo explica WALDRON, el discurso del odio tiene como blanco a una minoría y su propósito es excluir socialmente a sus miembros, atribuyéndoles características que les impiden vivir en sociedad. Por tanto, las manifestaciones de grupos minoritarios contra el orden establecido o contra las autoridades gubernamentales no cabrían en el concepto del discurso del odio, aun cuando pretendan incentivar el odio contra los grupos dominantes. Lo anterior no quiere significar que tales expresiones sean lícitas, pero la legalidad de la prohibición de este tipo de discurso se valorará conforme a los criterios previstos en el parágrafo $2 .^{\circ}$ del artículo $10 .^{\circ}$ del Convenio; análisis en el que el TEDH será proclive a admitir aquellas manifestaciones sobre asuntos de interés público que, pese a su tono provocador, no constituyen una incitación efectiva al uso de la violencia.

Por el contrario, la ilegalidad del discurso del odio se da por sentada, omitiéndose por parte del TEDH el análisis de la necesidad de su prohibición para el cumplimiento de las finalidades previstas en el ya citado parágrafo $2^{\circ}$. En especial, el TEDH no entra a valorar si las manifestaciones racistas, xenófobas o antisemíticas cuentan con una base fáctica o aportan algo al debate sobre los asuntos públicos. El TEDH no condiciona la convencionalidad de la prohibición del discurso del odio a que las expresiones censuradas tengan aptitud para motivar el uso de la violencia contra el grupo minoritario difamado. Tampoco exige el TEDH que su difusión se haya dado a través de medios masivos de comunicación; hasta el punto de que el mero hecho de colgar en una ventana un cartel con un mensaje xenófobo es considerado por el TEDH como una conducta inaceptable a la luz del Convenio ${ }^{45}$.

Lo anterior se evidencia en múltiples pronunciamientos del TEDH, de los cuales a modo de ejemplo permítaseme reseñar los siguientes.

En Jersild c. Dinamarca, el TEDH consideró contraria al Convenio la condena proferida contra un periodista que emitió al aire un reportaje acerca de un grupo neonazi, cuyos miembros aparecían lanzando arengas de contenido racista como "Los negros no son seres humanos". Si bien el Tribunal amparó los derechos del periodista demandante al estimar que se limitó a reproducir lo dicho por sus entrevistados y que su finalidad era generar un debate público sobre el tema, también señaló que expresiones como las lanzadas por

44 Ver, entre otros, Erbakan c. Turquía (2006) y Günduz c. Turquía (2003).

45 Cfr. Tribunal Europeo de Derechos Humanos, Norwood c. El Reino Unido, 16 de noviembre de 2004. 
el grupo neonazi, "al constituir serios insultos contra distintos grupos, no gozaban de la protección del artículo 10 del Convenio" 46 .

En el caso Garaudy c. Francia (2003) se cuestionaba la convencionalidad de la sentencia penal proferida contra un escritor que publicó un libro en el que negaba la existencia del Holocausto del pueblo judío durante la Segunda Guerra Mundial y atribuía la difusión de este "engaño" a una conspiración sionista. En criterio de las autoridades francesas, la conducta del demandante transgredió la ley nacional que prohíbe "la negación de crímenes contra la humanidad, difamación racial e incitación al odio por motivos de raza".

En su decisión el TEDH desestimó las pretensiones del demandante al considerar que "la negación de crímenes contra la humanidad es una de las formas más serias de difamación racial contra los judíos y de incitación al odio contra ellos [...]. Estos actos son incompatibles con la democracia y los derechos humanos porque infringen los derechos de los demás. Sus defensores tienen indudablemente unos propósitos que entran dentro de la categoría de los fines prohibidos por el artículo 17 del Convenio" 47 .

En Norwood c. el Reino Unido (2004) el TEDH conoció de los siguientes hechos: poco después del ataque terrorista contra el World Trade Center de la ciudad de Nueva York, el dirigente local de un partido de derecha colgó en la ventana de su casa un gran cartel con la fotografía del edificio en llamas y un letrero en el que se decía: "Fuera el islam de Gran Bretaña. Protejamos al pueblo británico". El demandante fue condenado bajo la sección 5. a del Public Order Act (1987) que prohíbe "exhibir ante una persona a la que pueda hostigar, causar alarma o angustia, cualquier escrito, símbolo o representación visible que sea amenazante, abusivo o insultante, como muestra de hostilidad hacia un grupo racial o religioso" 48 . En criterio del demandante la condena en su contra vulneró su derecho a la libertad de expresión garantizado en el artículo $10{ }^{\circ}$ del Convenio, pretensión frente a la cual consideró el TEDH:

El propósito general del artículo 17 es prevenir que individuos o grupos con intereses totalitarios exploten en su propio beneficio los principios enunciados en el Convenio. El Tribunal, y anteriormente la Comisión Europea de Derechos Humanos, ha considerado que en particular el derecho a la libertad de expresión

46 Tribunal Europeo de Derechos Humanos, Jersild c. Dinamarca, 23 de septiembre de 1994, n. 35.

47 Tribunal Europeo de Derechos Humanos, Garaudy c. Francia, 24 de junio de 2003. MarTín SÁnchez. Ob. cit., p. 10.

48 Trad. del autor; el original en inglés reza: "The applicant was then charged with an aggravated offence under section 5 of the Public Order Act 1986 (see below), of displaying, with hostility towards a racial or religious group, any writing, sign or other visible representation which is threatening, abusive or insulting, within the sight of a person likely to be caused harassment, alarm or distress by it": Tribunal Europeo de Derechos Humanos, Norwood c. el Reino Unido, 16 de noviembre de 2004. 
garantizado bajo el artículo $10{ }^{\circ}$ del Convenio, no puede ser invocado en contravención del artículo 17.

\section{$[\ldots]$}

El Tribunal reconoce y comparte las consideraciones formuladas por las Cortes nacionales, en el sentido de que palabras e imágenes como las contenidas en el póster constituyen la expresión pública de un ataque contra todos los musulmanes del Reino Unido. Tan generalizado y vehemente ataque contra un grupo religioso, consistente en vincular a dicho grupo como un todo con un grave acto terrorista, es incompatible con los valores proclamados y garantizados en el Convenio; a saber: tolerancia, paz social y no discriminación. El acto del demandante de colgar el póster antes referido en la ventana de su casa constituye un acto encuadrable en los supuestos del artículo 17, que, en consecuencia, no goza de protección por los artículos 10 y 14 del Convenio ${ }^{49}$.

Finalmente, en el caso Vejdeland c. Suecia (2012) el TEDH se pronunció acerca de la convencionalidad de la condena proferida contra un grupo de jóvenes, quienes de forma arbitraria irrumpieron en la sede de una escuela secundaria y dejaron en los casilleros de los alumnos más de 100 panfletos en los que se afirmaba lo siguiente: i) que la homosexualidad constituye una desviación sexual que destruye las bases morales de la sociedad; ii) que la difusión del virus del VIH obedece a la promiscuidad de los homosexuales, a quienes se les identificaba como la principal razón de esta "plaga de la modernidad"; iii) que las organizaciones homosexuales abogaban por la legalización de la pedofilia.

Los demandantes fueron condenados conforme al artículo 18 del código penal sueco que castiga el hostigamiento (agitation) contra un grupo nacional o étnico; disposición en la que también se incluye a los grupos identificados por sus tendencias sexuales. En criterio del TEDH la condena contra los demandantes no vulneró su derecho a la libertad de expresión, a pesar de que estos manifestaban que su intención era generar un debate público acerca de la

49 Trad. del autor; el original en inglés reza: "The general purpose of Article 17 is to prevent individuals or groups with totalitarian aims from exploiting in their own interests the principles enunciated by the Convention. The Court, and previously, the European Commission of Human Rights, has found in particular that the freedom of expression guaranteed under Article 10 of the Convention may not be invoked in a sense contrary to Article 17. [...] The Court notes and agrees with the assessment made by the domestic courts, namely that the words and images on the poster amounted to a public expression of attack on all Muslims in the United Kingdom. Such a general, vehement attack against a religious group, linking the group as a whole with a grave act of terrorism, is incompatible with the values proclaimed and guaranteed by the Convention, notably tolerance, social peace and non-discrimination. The applicant's display of the poster in his window constituted an act within the meaning of Article 17, which did not, therefore, enjoy the protection of Articles 10 or 14": ibíd. 
posición asumida por el sistema educativo sueco frente a la homosexualidad. Al respecto afirmó el Tribunal:

El Tribunal reitera que la incitación al odio no necesariamente debe comportar el llamado a la comisión de actos violentos o criminales. Insultar, ridiculizar o difamar a un grupo específico de la población puede ser suficiente para que las autoridades estatales adopten medidas para combatir el discurso del odio, como un modo irresponsable de ejercicio de la libertad de expresión [...]. Al respecto, el Tribunal considera que la discriminación basada en la orientación sexual es tan grave como la discriminación por motivos de "raza, origen o color" ${ }^{0}$ 51.

Sobre la base de las decisiones reseñadas parece acertado señalar que el TEDH asume frente al discurso del odio un enfoque restrictivo, conforme al cual la difamación de una colectividad no tiene ningún interés para el debate de los asuntos públicos y puede ser objeto de prohibición penal; incluso cuando no lleva aparejada la incitación al uso de la violencia o de otra actividad delictiva. El Tribunal parece haber optado por un concepto amplio de discurso del odio, en el que cabe cualquier incitación a la discriminación, independientemente de que la misma obedezca a consideraciones raciales, religiosas o de orientación sexual.

Autores como Juan María Bilbao Ubillos sostienen que la posición del Tribunal puede ser catalogada como de prevención debido a "las nefastas consecuencias de la libre difusión de ideas con un alto grado de toxicidad, de peligro para la convivencia [...] [L]os traumas del pasado, de un pasado relativamente reciente aún, explican la especial sensibilidad de la mayoría de las sociedades europeas en este terreno" ${ }^{52}$.

\section{CONCLUSIÓN}

De este breve estudio considero válido concluir que existe suficiente fundamento en el derecho internacional de los derechos humanos para afirmar

50 Trad. del autor; el original en inglés reza: "55. Moreover, the Court reiterates that inciting to hatred does not necessarily entail a call for an act of violence, or other criminal acts. Attacks on persons committed by insulting, holding up to ridicule or slandering specific groups of the population can be sufficient for the authorities to favour combating racist speech in the face offreedom of expression exercised in an irresponsible manner [...]. In this regard, the Court stresses that discrimination based on sexual orientation is as serious as discrimination based on race, origin or colour)". Tribunal Europeo de Derechos Humanos, Vejdeland y otros c. Suecia, 9 de febrero de 2012, n. 55.

51 En contra de lo considerado por el Tribunal Europeo de Derechos Humanos en esta decisión, ver KISKA. Ob. cit.

52 Juan María Bilbao Ubillos. "La negación del holocausto en la jurisprudencia del Tribunal Europeo de Derechos Humanos: la endeble justificación de tipos penales contrarios a la libertad de expresión", Revista de Derecho Político 71,2008, pp. 17-56. 
la existencia de un auténtico deber de prohibición del discurso del odio, aun cuando los instrumentos internacionales fallan a la hora de brindar una definición más o menos precisa de este concepto.

Este deber se circunscribe a la limitación en casos especiales del ejercicio de la libertad de expresión, en situaciones que han sido previstas por el derecho internacional de los derechos humanos y que devendrían en violencia encaminada a la comisión de genocidio por motivos discriminatorios. Pero no solo se han contemplado limitaciones y sanciones para comportamientos que pretendan el exterminio de un grupo minoritario, sino que también se vislumbra una nueva tendencia hacia la prohibición de la difusión de este tipo de ideas racistas.

En procura de esta precisión, resulta de suma utilidad lo considerado por JeREMy WaldRon en su obra The Harm in Hate Speech, en la que expone que el discurso del odio es un atentado contra la dignidad de los miembros de las colectividades difamadas, quienes se ven privados de su derecho a ser considerados como individuos aptos para la vida en sociedad. Además, el discurso del odio desfigura las sociedades, haciéndolas parecer un escenario hostil para que los miembros de las minorías atacadas puedan desarrollar su vida con normalidad. Efectos nocivos y palpables que ameritan la prohibición del discurso del odio.

La Corte Suprema de Estados Unidos apunta y reitera con sus providencias el enfoque liberal frente al hate speech, que se traduce en una tolerancia mayor por parte de las autoridades gubernamentales respecto del discurso al odio; se opta de esta forma indiscutiblemente por el respeto a la libertad de expresión. Contrario a esta posición se ubica el Tribunal Europeo de Derechos Humanos que califica como abuso de poder tales manifestaciones, por estimar que quebrantan los valores de dignidad y respeto en los que se funda el Convenio.

La tesis de WALDRON parece encontrar eco en la jurisprudencia del TEDH, que identifica los verdaderos casos de discurso del odio como una forma de abuso del derecho proscrita por el artículo 17 del Convenio, cuya prohibición no está condicionada a que el mensaje discriminatorio también lleve aparejada la incitación a la violencia; anacrónico requisito que en la actualidad solo es exigido por la jurisprudencia norteamericana.

\section{REFERENCIAS BIBLIOGRÁFICAS}

Alcácer Guirao, Rafael. "Discurso del odio y discurso político: en defensa de la libertad de los intolerantes", Revisa Electrónica de Ciencia Penal y Criminología, n. ${ }^{\circ}$ 14-02, 2012, p. 02:1-01:32.

Díaz Álvaro, Paúl. "La penalización de la incitación al odio a la luz de la jurisprudencia comparada", Revista Chilena de Derecho, vol. 38, n. . 3, 2011. 
Díaz Álvaro, Paúl. "The criminalization of hate speech in chile in light of comparative case law", Revista Chilena De Derecho, vol. 38, n. ${ }^{\circ}$ 2, 2011.

Fiss, Owen. The Irony of Free Speech, Cambrigde, MA, Harvard University Press, 1996.

Klanwatch Proyect. Ku Klux Klan, A History of Racism and Violence, 6. ${ }^{\text {a }}$ ed., Montgomery, Alabama, Southern Poverty Law Center, 2011.

KISKa, Roger. "Hate speech: A comparison between the European Court of Human Rights and the United States Supreme Court jurisprudence", Regent University Law Review, vol. 25:107.

LAIR, ERIC. "Reflexiones acerca del terror en los escenarios de guerra interna", Revista de Estudios Sociales, n. ${ }^{\circ}$ 15, junio, 2003.

Marco, Jorge. "De genocidios, holocaustos, exterminios...", en Gómez Bravo Gutmaro, Aróstegui Julio (coord.), Hispania Nova. Revista de Historia Contemporánea, n. ${ }^{\circ}$ $10,2012$.

Pérez-Madrid, Francisca. "Incitación al odio religioso o "hate speech" y libertad de expresión", Revista General de Derecho Canónico y Derecho Eclesiástico del Estado, no. $19,2009$.

Revenga Sánchez, Miguel. "Algunos apuntes sobre la doctrina del Tribunal Europeo de Derechos Humanos en materia de libertad de expresión", aA.vv., Miguel Revenga Sánchez y Andrée Viana Garcés (eds.), Tendencias jurisprudenciales de la Corte Interamericana y el Tribunal Europeo de Derechos Humanos, Valencia, Tirant lo Blanch, 2008.

Sánchez Isidoro, Martín. "El discurso del odio en el ámbito del Consejo de Europa", Revista General de Derecho Canónico y Derecho Eclesiástico del Estado n. . 28, 2012.

Ubillos Bilbao, Juan María. "La negación del Holocausto en la jurisprudencia del Tribunal Europeo de Derechos Humanos: la endeble justificación de tipos penales contrarios a la libertad de expresión", Revista de Derecho Político 71, 2008, pp. 17-56.

Waldron, Jeremy. The Harm in Hate Speech, London, Harvard University Press, 2012.

\section{Tribunal Europeo de Derechos Humanos}

Handyside c. El Reino Unido [1979].

Jersild c. Dinamarca [1994].

Karatas c. Turquía [1999]

Garaudy c. Francia [2003]

Günduz c. Turquía [2003].

Norwood c. El Reino Unido [2004]. 
Erbakan c. Turquía [2006].

Vejdeland c. Suecia [2012].

Corte Suprema de Estados Unidos

Brandenburg vs. Ohio [1969].

Collin vs. Smith [1978].

Snyder vs. Phelps et al. [2011]. 